\title{
Pedro Cerrillo: compañero, maestro y amigo'
}

\section{Pedro Cerrillo: Colleague, Master, and Friend}

\author{
SANTIAGO YUBERO \\ Director del CEPLI- Universidad de Castilla-La Mancha \\ España \\ santiago.yubero@uclm.es
}

(Recibido: O3-II-2OI8;

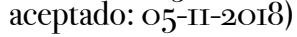

El 5 de julio de 2018 nos dejaba, tras una larga enfermedad, Pedro C. Cerrillo, doctor en Filología Hispánica y Catedrático de Didáctica de la Lengua y la Literatura de la Universidad de Castilla-La Mancha. Pedro C. Cerrillo ha sido un referente de los estudios en Literatura Infantil, consolidando académicamente el campo de la Didáctica de la Literatura, con una actividad investigadora que ha sido reconocida a nivel nacional e internacional con distinciones como el segundo Premio Nacional de Literatura Infantil a la mejor labor crítica del año (I98I) y la medalla a la Trayectoria como Investigador Internacional en Humanidades de la Universidad Nacional de México (20I8). Pedro Cerrillo es sin duda una figura imprescindible en los estudios sobre literatura infantil, sobre la lectura y la educación literaria, y sobre la formación de mediadores. Además, una de sus mejores cualidades ha sido la formación de equipos, que han conseguido tejer redes para realizar trabajos de reconocimiento internacional. Por ello, es difícil acercarse a la figura de Cerrillo y a lo que su trabajo supuso para la Didáctica de la Lengua y la Literatura y, en especial, para el afianzamiento de los estudios sobre la Literatura Infantil y la formación de mediadores en España, sin hacer referencia al Centro de Estudios para la Promoción de la Lectura y la Literatura Infantil (CEPLI) de la Universidad de Castilla-La Mancha, que él mismo fundó y desarrolló en compañía de un grupo de especialistas e investigadores de distintas disciplinas.

\footnotetext{
${ }^{\text {I }}$ Para citar este artículo: Yubero, S. (2019). Pedro César Cerrillo Torremocha: compañero, maestro y amigo. Álabe 2o. [www. revistaalabe.com]

DOI: I0.I5645/Alabe2OI9.20.I3
} 
En 1999 se crea el CEPLI, bajo la dirección de Pedro Cerrillo, con la intención de potenciar el desarrollo de las investigaciones en torno a la lectura y la literatura infantil y con el objetivo de avanzar en la creación de materiales y proyectos para la intervención en el ámbito de la lectura. En sus inicios, a partir del año 199I, los Cursos de Verano de la Universidad de Castilla-La Mancha sobre Literatura Infantil y Juvenil, dirigidos por el mismo Pedro Cerrillo y por Jaime García Padrino, que reunieron a gran número de especialistas y profesionales del ámbito de la Filología y la Lectura, sirvieron como germen para la creación del CEPLI, junto con otros cursos realizados para profesores y una experiencia que duró más de una década de un proyecto de divulgación semanal en las páginas de la prensa regional castellano-manchega de aspectos teóricos y actividades prácticas sobre literatura infantil para maestros y alumnos. Pedro Cerrillo, junto con un equipo multidisciplinar formado por profesores universitarios de Filología, Psicología, Pedagogía y también por maestros, bibliotecarios y educadores sociales, siguió trabajando durante muchos años hasta la mencionada creación del CEPLI. Un Centro que recogió los frutos del trabajo previo realizado, pero que tuvo la visión de planificar y proyectar la investigación en un ámbito muy denostado y, posiblemente, despreciado entonces en el mundo universitario, como es el de la Literatura Infantil. El CEPLI nació con el objetivo de potenciar la investigación y desarrollar una formación especializada en el mundo de la lectura y los libros infantiles y, para ello, centró su tarea en la elaboración y desarrollo de numerosos proyectos de investigación, de los que han nacido a lo largo de todos estos años multitud de publicaciones de libros y de artículos en revistas especializadas. En el CEPLI también se planificó la creación del primer Máster de nuestro país en Promoción de la Lectura y la Literatura Infantil y, además, se creó una biblioteca universitaria especializada en Literatura Infantil que, con la adquisición inicial de 8.ooo volúmenes del fondo de Carmen Bravo Villasante, comenzó su andadura allá por el año 2000 llegando a alcanzar en la actualidad cerca de 25.0oo volúmenes y un fondo antiguo digitalizado de 3000 libros, siendo un referente entre las mejores bibliotecas del mundo.

Durante todos estos años el CEPLI ha programado y realizado numerosos congresos internacionales y jornadas con especialistas, siendo de gran relevancia los Congresos de Educación Social y Alfabetización Lectora, así como los Congresos de Literatura Popular de Tradición Infantil. Pedro Cerrillo creó y consolidó el grupo de investigación LIEL, destacado por sus estudios sobre Literatura Infantil, Educación Literaria y Literatura Popular de Tradición Infantil, manteniendo también una estrecha y cercana relación para la elaboración de distintos proyectos con relevantes instituciones y fundaciones de renombre en estos ámbitos, como Fundalectura (Colombia), IBBY (México), Fundación Cuatro Gatos (EE.UU), Instituto de la Mujer, Fundación Botín, Red Internacional de Universidades Lectoras y Fundación SM, entre otras. En el año 2005, Pedro Cerrillo fue cofundador de la revista científica Ocnos. Estudios sobre lectura, que en la actualidad es un referente internacional en la divulgación científica en el ámbito de la lectura 
y la literatura que, de la mano de otras revistas prestigiosas como Álabe y Lenguaje y Textos, buscan ser referencia de las publicaciones de las investigaciones realizadas en el ámbito lector y literario en nuestro país y Latinoamérica.

Sin duda, como ya han señalado otros, Pedro C. Cerrillo es un modelo a seguir en la investigación y en la acción educativa. Sus contribuciones teóricas e investigaciones han sido, son y serán esenciales para todos los investigadores y profesionales del campo de la Didáctica de la Lengua y la Literatura. Estamos, sin duda, ante un hombre defensor a ultranza de las Humanidades. Un humanista que siempre amó la palabra y la lectura, y un pionero de los estudios de Literatura Infantil en la universidad española. Hablamos de un investigador riguroso y un docente respetado, además de un excelente gestor de grupos. Pedro C. Cerrillo, a lo largo de su vida, ha sido respetuoso con todos y honesto consigo mismo y con los demás y, además, un excelente amigo. 